\title{
Explorando mágicas em aulas de Física ${ }^{+*}$
}

Anderson Coser Gaudio ${ }^{1}$

TecnoLab - Laboratório de Desenvolvimento e Aplicação de Novas

Tecnologias no Ensino de Física

Departamento de Física - CCE - UFES

Vitória - ES

\section{Resumo}

Os vídeos postados no YouTube podem ser muito úteis em sala de aula, independentemente da área de conhecimento. Na área de Física, existe farto material esperando apenas que os professores saibam o que fazer com eles. Neste trabalho, apresentamos um relato de como utilizamos vídeos de números de mágica como material pedagógico auxiliar em aulas de Física. Como o objetivo da mágica é desafiar um princípio ou uma lei natural, torna-se interessante seu uso com o objetivo de tentar desvendar seu segredo de forma científica. Para ilustrar a aplicação desta estratégia, usamos uma apresentação do mágico Dynamo, realizada em Londres, em que ele caminha tranquilamente sobre as águas do rio Tâmisa. Uma vez superada a surpresa da ilusão, os alunos são conduzidos pelo professor a tentar obter uma explicação fisicamente plausível para o segredo da mágica. Para levar a cabo esta tarefa, seguimos os passos do chamado método científico em sua forma tradicionalmente definida nos livros escolares. Os resultados obtidos são muito positivos, uma vez que se observa claramente o engajamento dos alunos na busca pela explicação correta. Essa estratégia é recomendada para uso nas aulas de Física do ensino médio e dos semestres iniciais de cursos universitários.

Palavras-chave: Mágica; Ilusionismo; Estratégia de ensino; Aula de Física; Aprendizagem significativa.

\footnotetext{
${ }^{+}$Using magic to improve Physics classes

* Recebido: setembro de 2014. Aceito: março de 2015.

${ }^{1}$ E-mail: anderson.gaudio@ufes.br
} 


\begin{abstract}
The videos posted on YouTube can be very helpful to teach any subject in the classroom. In Physics, there is a wealth of material just waiting for the teachers to know what to do with them. In this study, we present a report on how we used videos of magic performances as a teaching aid to supplement Physics classes. Since the goal of magic is to challenge a principle or a natural law, it is interesting to use it in order to try to unravel its secret in a scientific way. To illustrate the application of this strategy, we used a performance of the magician Dynamo, held in London, where he quietly walks on the water of the River Thames. Having overcome the surprise of illusion, students are led by the teacher to try to get a physically plausible explanation for the secret of the magic. To carry out this task, we followed the paths of so-called scientific method in their traditionally defined form in schoolbooks. The results are very positive as and clearly point out the engagement of students in the search for the correct explanation. This strategy is recommended for use in high school Physics classes and in the initial semesters in College courses.
\end{abstract}

Keywords: Magic; Illusionism; Teaching strategy; Physics class; Meaningful learning.

\title{
I. Introdução
}

Alguma vez você se perguntou sobre o motivo de as pessoas sentirem-se tão atraídas por números de mágica? A mágica pode ser vista como um mecanismo de escape da realidade física em que vivemos. Quando vemos um grande mágico ${ }^{2}$ em ação, nossa mente, mesmo que involuntariamente, abre espaço para o sobrenatural. Afinal, como é possível andar apenas com a metade do corpo (COPPERFIELD, 2013), fazer desaparecer a Estátua da Liberdade (COPPERFIELD, 1983) ou atravessar a Muralha da China (COPPERFIELD, 1986) na frente de centenas de espectadores? Apesar do deleite que nos proporciona, a mágica traz embutido um perigo potencial. Diante de apresentações como essas, as pessoas podem começar a acreditar que as leis da Física não são plenamente aplicáveis a todas as pessoas ou a todas as situações. Este sentimento pode confortar alguns, pois sendo possível a mágica "verdadeira", ou seja, a mágica em que as coisas acontecem sem ilusão, isso poderia fortificar crenças pseudo-

\footnotetext{
2 O termo "mágico" é tecnicamente inadequado, pois sugere que o artista possui poderes sobrenaturais. Seria preferível o termo "ilusionista" para se referir ao profissional da mágica, uma vez que seu trabalho consiste em iludir o público. No entanto, como no Brasil não se costuma fazer distinção entre um termo e outro, não nos esforçaremos para diferenciá-los neste trabalho.
} 
científicas (e.g., previsões do horóscopo) e sobrenaturais (e.g., fantasmas), bem como crenças em fenômenos ainda não explicados pela ciência (e.g., milagres). Talvez por isso algumas pessoas podem não se interessar em saber como a ilusão da mágica é realizada. A desmistificação da mágica poderia abrir caminho para fazer desmoronar crenças de valor, o que algumas pessoas possivelmente não tolerariam.

A história da mágica remonta a tempos imemoriais, sendo que este artigo não tem a intenção de se perder em meio a uma longa exposição sobre o assunto. Como se trata de um tema que não possui caráter científico, sugerimos ao leitor interessado o artigo "Magic (illusion)", na versão inglesa da Wikipedia (WALES, 2015). No que concerne aos nossos interesses, partimos de meados da década de 1980, quando a prática da mágica ainda envolvia a utilização de equipamentos caros e sofisticados, que faziam amplo uso de fundos falsos, espelhos retráteis, exoesqueletos, partes do corpo humano feitos de material sintético, etc. Muitos desses números de mágica podiam ser vistos em programas de auditório nas TVs do mundo inteiro. Embora fosse interessante, esse estilo de mágica aparentemente tornou-se um tanto enfadonho. Neste caso, os mágicos passavam mais tempo manipulando seus equipamentos do que fazendo mágica propriamente dita, pois mesmo nesse tipo de apresentação espera-se um pouco de prestidigitação. Nessa época, alguns mágicos jovens e impetuosos começaram a incorporar técnicas inovadoras que elevaram o patamar da mágica e possibilitaram a execução de números grandiosos, em que até a Estátua da Liberdade pôde desaparecer na frente de espectadores. Foi uma renovação na arte da mágica. O maior expoente dessa época foi o estadunidense David Copperfield, que revolucionou o mundo do ilusionismo e estabeleceu um novo padrão para a mágica.

Nos anos de 1997 e 1998, a rede de TV Fox, nos Estados Unidos, e Sky e ITV, no Reino Unido, apresentaram a série Breaking the Magician's Code: Magic's Biggest Secrets Finally Revealed (VALENTINO, 1997) (Quebrando o Código dos Mágicos: grandes segredos da mágica finalmente revelados). A ideia mais excitante do show repousava no chamado código de honra dos mágicos, que pró́be a revelação de seus segredos sob a pena de banimento pelos colegas de profissão. E era justamente o tal código que se propunha quebrar nesse programa. Por conta disso, o ilusionista estadunidense Val Valentino, estrela do show, apresentava-se usando máscara. Como seu nome também tinha de ser mantido em segredo, ele acabou sendo cognominado Masked Magician (Mágico Mascarado). Em 1998 e 1999, o sucesso estrondoso do programa fez com que ao menos partes dele fossem apresentadas em TVs de vários países. Em 1999, alguns números de mágica reveladores foram exibidos no programa Fantástico da Rede Globo (VALENTINO, 1999), em que o mágico foi batizado Mr. M, o "senhor de todos os segredos" ou o "príncipe negro dos sortilégios" (quem com mais de trinta anos não se lembra da voz tenebrosa de Cid Moreira?). Foram muitas as versões do programa original da Fox criadas ao redor do mundo, sendo que algumas ainda são exibidas aqui e ali.

As revelações de Mr. M foram um duro golpe nos mágicos. Após tanto investimento em equipamentos caros pouco restou que pudesse ser visto com surpresa. Assim, mais uma 
vez os mágicos tiveram que evoluir para que não fossem extintos. A partir de 1998 e ao longo da década de 2000 foram aparecendo jovens mágicos cujos números pareciam não ter explicação razoável. Foi o caso de David Blaine, que era especialista em submeter o próprio corpo a limites impensáveis. Embora não tenha sido quem inventou, Blaine foi quem popularizou a chamada mágica de rua com estilo hit and run, em que o mágico caminha pelas ruas, aborda transeuntes, faz uma mágica rápida e vai embora deixando a pessoa boquiaberta. Nessa linha, dois mágicos alcançaram o patamar mais elevado. São eles Criss Angel e Dynamo.

Esses "novos mágicos" abandonaram as mágicas grandiosas, caras e não tão interessantes, em prol de números pontuais, inesperados e estranhos a ponto de causar medo nas pessoas. Por exemplo, como alguém pode ser capaz de ler o pensamento de outra pessoa? Não pode, é claro. Mas esse tipo de mágica faz com que muitos comecem a ver esses profissionais como possuidores de algum poder sobrenatural. Em paralelo, tornou-se mais difícil desvendar seus segredos. Assim, mais uma vez a TV, ansiosa pela busca de audiência, logo começou a tirar proveito desse fenômeno.

Assim, o inglês Derren Brown estreou na televisão do Reino Unido em dezembro de 2000 com a série "Derren Brown: Controle da Mente" (BROWN, 2000). David Blaine participou de diversos especiais de TV como "David Blaine: Street Magic" (BLAINE, 1997) e "David Blaine: Magic Man" (BLAINE, 1998). A série de Criss Angel, chamada "MindFreak" (ANGEL, 2005), é o mais bem-sucedido show de mágica na história da TV. Dynamo ganhou seu primeiro prêmio na TV, quando "Dynamo: Mágica do Impossível" (FRAYNE, 2011) venceu na categoria Melhor Programa de Entretenimento do UK Broadcast Awards.

Por outro lado, em março de 2013, o canal por assinatura Discovery Channel começou a exibir uma série de programas denominada "A Ciência Mágica” (HANLIN et al., 2013), em que quatro ilusionistas apresentam números de mágica de natureza mais tecnológica e revelam seus segredos com base em princípios de Física e Química. Neste caso, não houve grande prejuízo para os demais mágicos, pois a maior parte dos números apresentados e esclarecidos não fazia parte de suas apresentações. Esse programa teve o mérito de nos lembrar de que a Física, bem como a Química, estão muito presentes nos números de mágica modernos. E isto abre a oportunidade de exploração desse universo nas aulas de Física dos ensinos médio e universitário.

Foi assim que começamos a explorar a mágica como estratégia de ensino no primeiro semestre de 2013, nas aulas introdutórias ministradas aos calouros do curso de Física de minha universidade. Incrivelmente, são raros os relatos de experiências como esta. Em nossa busca, detectamos o trabalho de Silveira e colaboradores, que desenvolveram o projeto teatral "Trupe da Magia" entre 2004 e 2005 com o objetivo de divulgar a ciência por meio de números de mágica (SILVEIRA; ATAÍDE; FREIRE, 2009). Recentemente, o periódico The Physics Teacher publicou o artigo "Martin Gardner: 100 Years of the Magic of Physics" (GILLASPY, 2014) que lembra o centenário de nascimento do filósofo e escritor a que se refere o título. Interessado em truques de mágica, entre muitos outros assuntos, Gardner con- 
tribuiu em diversas oportunidades para a seção Physics Trick of The Month daquele periódico, em que descreve pequenos truques de mágica e os explica em termos físicos. Uma seleção dessas contribuições está disponível no Martin Gardner Centenial Collection da American Association of Physics Teachers (GARDNER, 2014).

Este artigo é um relato que tem a pretensão única de fazer conhecer aos colegas professores de Física, em nível médio e superior, sobre o potencial pedagógico da mágica. Para isso, farei uso de um exemplo que será detalhado nas seções seguintes.

\section{Usando a mágica em sala de aula}

Ao trazer a mágica para dentro da sala de aula, aumentam as chances de que haja interesse, debate e trocas de ideias, mantendo-se o foco no assunto em questão. Ou seja, é algo que o professor de Física poderá desejar em sua aula. Mas como explorar essa estratégia de ensino para, de fato, fazer com que os alunos aprendam Física (e não mágica)?

Para tentar tirar proveito da mágica em sala de aula, decidimos por usar algo parecido com os temas geradores utilizados por Delizoicov e Angotti em seus Três Momentos Pedagógicos (Aula 3MP) (DELIZOICOV; ANGOTTI, 1992). Como sabemos, esta abordagem é baseada nas palavras geradoras, utilizadas por Paulo Freire em seu famoso e bem sucedido método de alfabetização de trabalhadores do campo (FREIRE, 1987).

As aulas 3MP fazem uso de um grande tema que é explorado ao longo de um semestre, ou até mesmo durante todo um ano letivo. É o caso da "Produção, distribuição e consumo de energia elétrica", tema gerador explorado no livro "Física" (DELIZOICOV; ANGOTTI, 1992). Mas há também os equipamentos geradores, artefatos tecnológicos utilizados no cotidiano, que podem ser explorados com a finalidade de aprendizado de leis físicas e suas aplicações práticas (ANGOTTI; BASTOS; MION, 2001). Ao contrário dos temas, os equipamentos geradores proporcionam material didático para apenas umas poucas aulas.

No caso do uso da mágica como mídia geradora (utiliza-se um vídeo com a exibição da mágica, ao invés de realiza-la) nossa experiência mostra que o proveito é maior quando a estratégia é aplicada em apenas uma aula. Isto porque o segredo da mágica, que pode ser mais interessante que a própria mágica, deve ser revelada ao aluno na mesma aula. Caso contrário, entre uma aula e outra eles poderão fazer buscas na internet que reduzirão o impacto da revelação. Por isso, este tipo de aula deve ser muito bem planejado. Também não devemos esquecer de que a escolha adequada do número de mágica é muito importante. Este deve ser potencialmente rico em princípios e leis da Física, embora não seja essencial que o segredo da mágica esteja baseado num fenômeno físico espetacular. Tem mais valor a lei física que o número sugere transgredir e a forma inusitada de fazê-lo.

Devido ao caráter próprio da mágica e da excitação que ela provoca, houve necessidade de nos desviar um pouco da estrutura da aula 3MP. Assim, procuramos seguir uma linha investigativa em que fizemos uso das regras básicas do método científico (ver adiante) para tentar chegar à explicação da mágica. 
Em relação ao aspecto cognitivo da aplicação da estratégia, temos trabalhado com os fundamentos da teoria da aprendizagem significativa de David Ausubel (MOREIRA, 1999; 2006; MOREIRA; MASINI, 2006), que se adequa bem às características específicas da área de ciências exatas. Mais importante, a estratégia ora apresentada força os alunos a buscar subsunçores em sua estrutura cognitiva com a finalidade de tentar explicar o segredo da mágica. Com isso, espera-se aquisição de elevado grau de aprendizagem significativa subordinada correlativa. A expressão verbal do esforço mental dos alunos dará ao professor a oportunidade de escrutinar o grau de conhecimento prévio da turma e, assim, melhor planejar suas futuras aulas. Ao final da aula, com o número de mágica descontruído passo a passo, espera-se que haja algum grau de unificação conceitual, que é a essência da aprendizagem superordenada.

Outra coisa importante: de forma semelhante ao uso de qualquer estratégia de ensino, recomendamos fazer uso apenas esporádico desta estratégia, pois há o receio de saturar o aluno com repetições. Finalmente, nossa experiência indica que o tempo de aula ideal para aplicação desta estratégia é de cerca de duas horas. A seguir, apresentamos o exemplo mais bem sucedido de nossa experiência com uso de vídeos de mágica em sala de aula.

\section{Andando sobre as águas}

De forma similar aos números de mágica, iniciei uma de minhas aulas de Física com algum suspense: projetei na tela uma antiga imagem de Cristo andando sobre as águas do mar da Galileia (Fig. 1). Sem falar nada, fiquei observando o semblante dos alunos por algum tempo em busca de reações. Aparentemente sem entender nada, muitos começaram a olhar para mim e para os colegas próximos. Então fiz apenas uma pergunta: o que vocês acham desta imagem? Naturalmente que é uma pergunta de duplo sentido e com forte potencial polêmico. Sendo assim, demorou algum tempo até que o primeiro aluno tomou coragem para se manifestar: "É Jesus Cristo andando sobre a água. Está na Bíblia". Alguns concordaram com esta observação. Mas, meio que sussurrando, um disse: "Mas isso não pode acontecer". Outro complementou: "É contra as leis da Física". Mas alguém ficou um pouco exaltado: "Mas foi um milagre!"’.

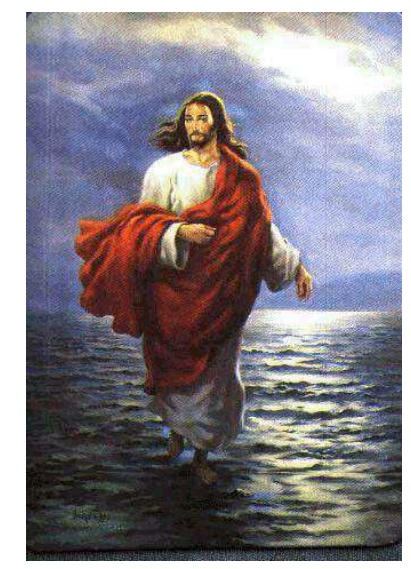

Fig. 1 - Cristo caminhando sobre as águas do Mar da Galileia. 
Neste momento, pedi silêncio à turma. Expliquei que nossa aula era de Física e não de religião. E que eu estava interessado na possibilidade de um homem comum (não um santo) ser capaz de andar sobre águas, da mesma forma como fez Cristo na famosa passagem bíblica. Neste momento tudo mudou e houve unanimidade em responder que isso não era possível. Ou seja, todos concordaram que nenhum ser humano é capaz de caminhar sobre uma lâmina d'água sem afundar, a menos que faça uso de alguma tecnologia auxiliar, como por exemplo, uma corda que o mantenha suspenso ou uma boia que o impeça de afundar.

Chegou então a hora de deleite do professor. Anunciei que nesse momento eles assistiriam a um vídeo que mostra uma situação inusitada (SIC, 2009). Trata-se do ilusionista inglês Steven Frayne, mais conhecido como Dynamo, que ficou mundialmente famoso com a série Mágica do Impossível (FRAYNE, 2011). Na apresentação, Dynamo passeia tranquilamente pela pista que margeia o rio Tâmisa, próxima ao Parlamento Britânico, em Londres. De repente, como se tivesse decidido naquele instante, ele desce uma escadaria que dá acesso direto ao rio. Após atravessar uma pequena plataforma flutuante, pisa cuidadosamente sobre a água do rio e... começa a andar (Fig. 2a). Ele consegue caminhar sobre as águas do Tâmisa em direção à outra margem, afastando-se cerca de trinta metros do local de onde saíra. E ali fica parado de braços abertos, exaltando seu feito (Fig. 2b). Ficou clara sua ironia ao tentar imitar Cristo. Após alguns instantes, uma lancha com (supostos) policiais se aproxima dele, o aborda e o leva embora como se fora prisioneiro. Como sabemos, a lei britânica proíbe nadar na parte urbana do Tâmisa. O curioso é que provavelmente não deve haver lei que proíba andar sobre o rio.

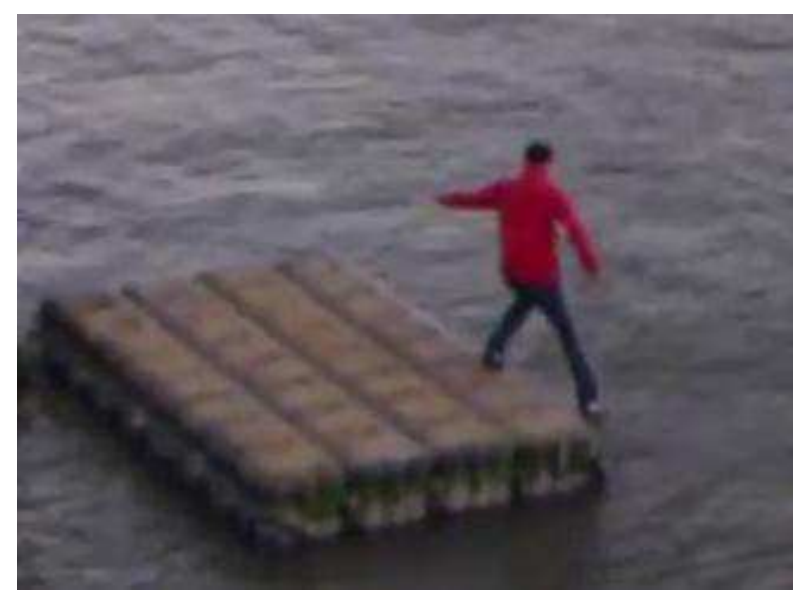

(a)

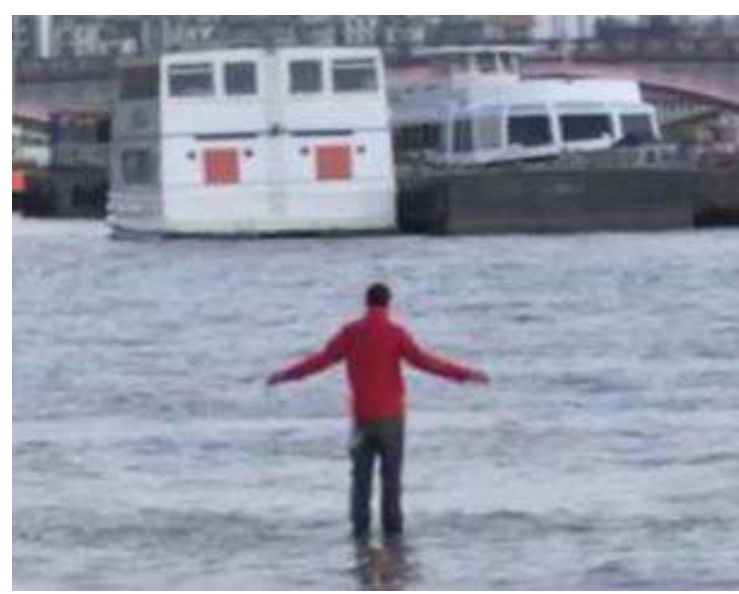

(b)

Fig. 2 - (a) Instante em que Dynamo pisa sobre as águas do rio Tâmisa, em Londres. (b) Momento de contemplação de contemplação e regozijo ao concluir a façanha (UKTV, 2011). 


\section{Procurando uma explicação}

Procurei seguir os passos do que se convencionou chamar de método científico para melhor organizar a etapa seguinte da atividade, qual seja a busca por uma explicação para o que os alunos acabaram de ver. Apesar de termos conhecimento das divergências que envolvem o método científico como mecanismo gerador de conhecimento científico (MOREIRA; OSTERMANN, 1993), o método pode ser muito útil para fins pedagógicos na medida em que dá ao aluno algum grau de organização para seu raciocínio. Segundo o método, após a observação de um fenômeno físico (neste caso, a mágica), a próxima etapa é a elaboração de uma ou mais hipóteses que tenham potencial para explicá-lo total ou parcialmente. Assim, abri a palavra para a proposição de hipóteses, com ampla liberdade de manifestação. Eis as hipóteses elaboradas:

(a) "Há uma corda invisível sustentando o mágico."

(b) "Ele consegue flutuar porque é muito magrinho."

(c) "Ele na verdade não anda sobre a água, pois afunda um pouco. Acho que isso faz a diferença."

(d) "Deve ter um mergulhador segurando os pés dele."

(e) "Ele deve ter algum poder que desconhecemos."

Todas as hipóteses foram escritas no quadro e o próximo passo foi tentar refutá-las, de acordo com o que preconiza Popper (POPPER, 2008). Para começar, refutamos imediatamente a hipótese (e), pois trabalhamos dentro do domínio da ciência física. Aproveitei a oportunidade para alertar a todos sobre a sedução que as pseudociências costumam exercer sobre nosso julgamento acerca dos fenômenos naturais.

A hipótese (a) foi também refutada pela grande maioria dos alunos, pois além de cordas invisíveis não existirem, seria também necessário alguma espécie de guindaste no qual a corda estaria amarrada. Só que o guindaste também deveria ser invisível para não despertar a atenção do público. Ou seja, havia muitas restrições fantásticas nesta hipótese e foi uma boa oportunidade para utilizar a Navalha de Occam (DOMINGOS, 1999), que fora assunto de aulas anteriores.

As hipóteses (b) e (c) puderam ser analisadas em conjunto, pois dizem respeito ao empuxo exercido pela água sobre o corpo do mágico. É bem verdade que os autores destas hipóteses podiam não ter conhecimento exato do que fosse a força de empuxo, pois eram calouros. Mas isso não tinha importância, pois as hipóteses geraram a oportunidade ideal para abordar esse assunto. E assim foi feito. Utilizei cerca de trinta minutos da aula para introduzir o conceito de empuxo e a definição de força de empuxo, bem como citar alguns poucos exemplos. Isto foi feito com o auxílio de uma apresentação em PowerPoint e do projetor multimídia, uma vez que havia sido prevista a necessidade deste material. Desta forma, o ganho de tempo foi sensível. 
Em seguida voltamos ao problema principal: a flutuação do mágico. Com a ideia de empuxo fresca na cabeça, demonstramos que pelo fato de ser muito magro e de baixa estatura, o mágico tem pequeno volume e pouca gordura corporal. Esta combinação torna seu corpo mais denso do que o da maioria das pessoas, especialmente as obesas. E o aumento da densidade dos corpos reduz sua capacidade de flutuação. Assim, não houve um só aluno que concordasse com a viabilidade das hipóteses (b) e (c), incluindo agora seus autores.

Portanto, restou apenas a hipótese (d) para ser analisada. Mais uma vez, deixei que os alunos opinassem sobre a possibilidade de um mergulhador apoiar os pés do mágico. Foram duas as razões contrárias a este argumento: o peso do mágico provavelmente afundaria o mergulhador e não havia indícios de bolhas na superfície da água ${ }^{3}$, produzidas pelo aqualung. Assim, a hipótese (e) também acabou sendo refutada. Mas todos concordaram que, uma vez que deve haver algum truque na apresentação, este deve estar sob a água. Esta certeza foi reforçada pela turbidez das águas do rio Tâmisa, que poderia facilmente esconder algum mecanismo de sustentação para o mágico.

Assim, abri nova rodada de elaboração de hipóteses para explorar dispositivos submarinos de sustentação. Desta vez não houve grande avanço. Alguém sugeriu a presença de mais de um mergulhador, todos equipados com aqualungs que não deixassem escapar bolhas. Quando questionado, o aluno não soube dizer se esta tecnologia existia ou não (na verdade, ela existe e o equipamento que a utiliza é chamado de rebreather, ou re-respirador). Seus colegas reafirmaram a impossibilidade de manter firme o apoio aos pés do mágico, mesmo com a presença de mais mergulhadores. Para mudar o assunto, outro aluno sugeriu que a água era bem rasa no lugar em que o mágico andou (alguns centímetros). Mas um dos colegas lembrou que havia caiaques com remadores circulando pelo local e, ao final do número, um barco resgatou o apresentador. Caso fosse tão raso assim, ao menos o barco encalharia. Assim, a hipótese foi abandonada e não chegamos a qualquer explicação razoável.

\section{Dando uma força para os alunos}

Antevendo resultado negativo para a explicação física do número apresentado por Dynamo, como de fato ocorreu, apresentei um novo vídeo aos alunos. Neste, o mágico Mr. M, também aparece andando sobre águas (SIC, 2009). Aqui ele atravessa uma piscina, ao longo de seu comprimento de cerca de 20 m. Só que ele não está só. Há diversos banhistas na piscina, acompanhando bem de perto sua caminhada (Fig. 3a). Numa tomada intrigante, uma mulher mergulha por baixo dos sapatos do mágico (Fig. 3b). Portanto, a combinação envolvendo a água límpida da piscina, a proximidade de expectadores (cerca de um ou dois metros) e o trânsito de mergulhadores por debaixo dos pés do mágico, torna o número bem mais intrigante e desafiador que o de Dynamo. Em um primeiro momento, o expectador fica estupefato e

\footnotetext{
${ }^{3}$ Ver observação sobre bolhas na água, adiante.
} 
sem explicações razoáveis a dar. Mas é claro que o título do vídeo, “Andando sobre a água revelada pela primeira vez", anuncia que logo saberíamos como o número é feito.

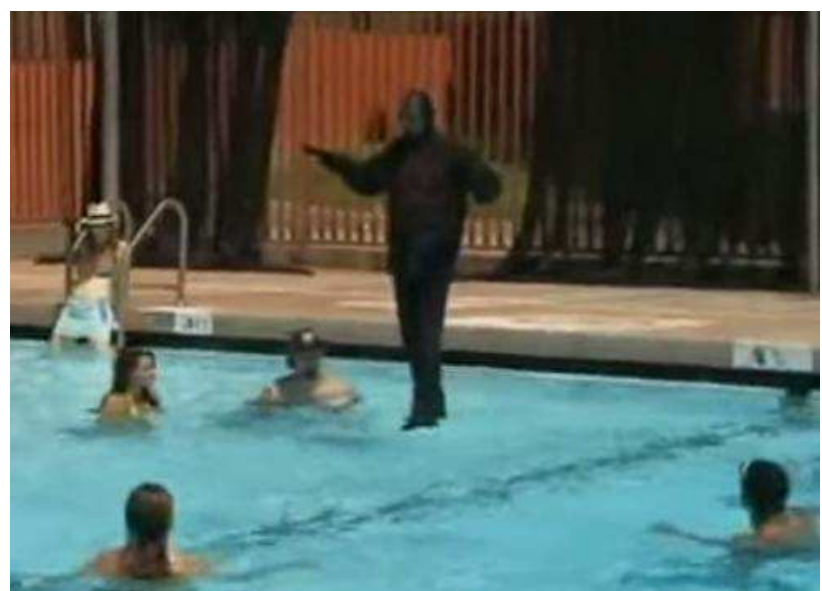

(a)

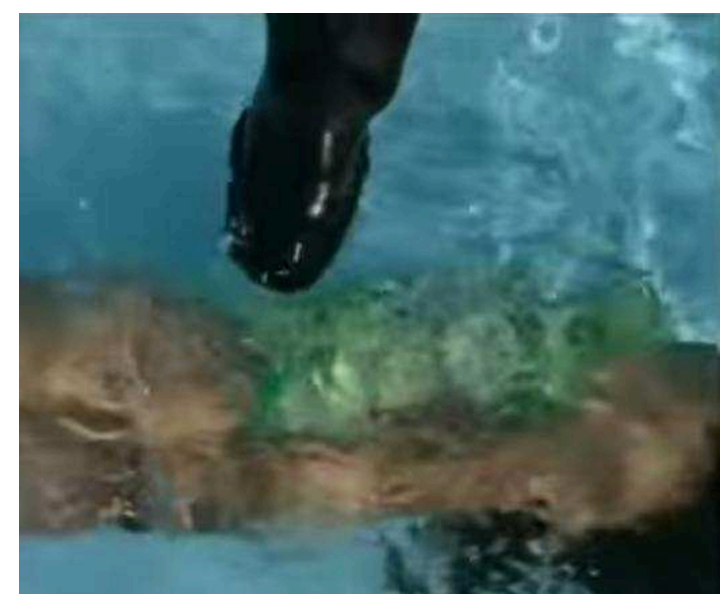

(b)

Fig. 3. (a) Mr. M caminha sobre as águas de uma piscina. (b) Uma mulher mergulha sob o andar do mágico (SIC, 2009).

A origem da fama de Mr. M repousa nos espetáculos em que ele revelava os truques por detrás de números apresentados por mágicos famosos. Ele fazia questão de exaltar sua condição marginal no mundo da mágica e as supostas ameaças de morte que recebia com frequência. Daí a necessidade da máscara que costumava usar nos shows. Portanto, após completar a travessia, era chegada a hora de desvendar o segredo. Confirmando a conclusão parcial a que os alunos haviam chegado, o truque estava sob a água. Neste caso, tratava-se de mesas de tamanhos variados, feitas integralmente de material acrílico e cuja extensão cobria todo o comprimento da piscina. O topo das mesas estava localizado a cerca de três centímetros abaixo da superfície da água. Mas, e quanto aos expectadores? Será que eles não notaram a presença das mesas? Na verdade, todas as pessoas que aparecem no vídeo não são expectadores comuns e sim pessoas contratadas pelo mágico para ajudar a disfarçar o segredo da apresentação.

\section{A Física dá uma força aos mágicos}

Em se tratando de um número de mágica usado como estratégia de ensino numa aula de Física, o professor não poderá deixar de explorar os aspectos físicos envolvidos, mesmo porque é exatamente este o motivo de sua exibição. Pelo fato de o vídeo de Mr. M ter sido postado em baixa definição, de ser narrado em português de Portugal e ser pouco audível no ambiente da sala de aula, a maioria dos alunos não conseguiu compreender direito as explicações dadas pelo locutor quando da revelação do truque. Assim, dediquei mais trinta minutos da aula para discutir esses aspectos. 
O acrílico possui índice de refração igual a 1,49, bem próximo ao da água pura, que é de 1,33. A presença de solutos na água da piscina faz com que este valor se aproxime um pouco mais daquele. Sabemos que quanto mais próximos forem esses índices, menos visível ficará a mesa submersa. Mesmo assim, a pequena diferença nos índices de refração não é capaz de camuflar completamente as mesas. É preciso cuidados extras. E aí se justifica a presença das pessoas durante a apresentação. Algumas delas ficam próximas às mesas movimentando a água. Isso dificulta a visualização do que está submerso pela alteração constante e irregular do ângulo de incidência dos raios de luz na superfície da água. Outra coisa que ajudou a disfarçar as mesas foi o uso apropriado da câmera. Nas tomadas de longe, a filmagem é feita num pequeno ângulo acima da horizontal, ou seja, com a câmera próxima à superfície da água. Assim foi possível tirar proveito do efeito do ângulo limite, em que a luz refletida na direção da câmera pela mesa submersa é refletida na superfície da água e não consegue sair da piscina (reflexão total). No caso das tomadas próximas ao mágico, houve o cuidado de não captar as bordas das mesas.

\section{Hora de revelar o segredo}

Assim, eu e os alunos voltamos a nos concentrar na apresentação inicial. Eu perguntei a eles se o recurso utilizado por Mr. M também poderia ser usado por Dynamo. De imediato os alunos reconheceram algumas diferenças entre as condições reinantes nos dois números. A estas, acrescentei outras que são mostradas no Quadro 1.

Quadro 1 - Comparação entre as condições reinantes durante as apresentações de Mr. M e de Dynamo.

\begin{tabular}{|l|l|l|}
\hline Condições & Mr. M (piscina) & Dynamo (rio Tâmisa) \\
\hline Água & Límpida & Turva \\
\hline Expectadores & $\begin{array}{l}\text { Cerca de uma dezena, con- } \\
\text { tratados e próximos. }\end{array}$ & $\begin{array}{l}\text { Cerca de uma centena, não contratados } \\
\text { e distantes. }\end{array}$ \\
\hline Tempo & Céu claro & Céu parcialmente nublado \\
\hline Hora do dia & Próximo ao meio-dia & Final da tarde. \\
\hline $\begin{array}{l}\text { Tomadas de câme- } \\
\text { ra }\end{array}$ & Cuidadosamente planejadas & Contra a luz do Sol \\
\hline Sob a água & $\begin{array}{l}\text { Fundo da piscina plano e } \\
\text { sólido. }\end{array}$ & $\begin{array}{l}\text { Leito do rio provavelmente irregular e } \\
\text { macio, mas não profundo. }\end{array}$ \\
\hline
\end{tabular}

Tendo em mente as diferentes condições citadas no Quadro 1 fica evidente que o número apresentado por Dynamo foi muito mais arriscado que o de Mr. M. Enquanto este trabalhou entre amigos e, portanto, sem possibilidade de errar, uma falha na apresentação de 
Dynamo poderia ter arruinado sua carreira. Portanto, mesmo as eventuais falhas devem ser capitalizadas a favor do mágico.

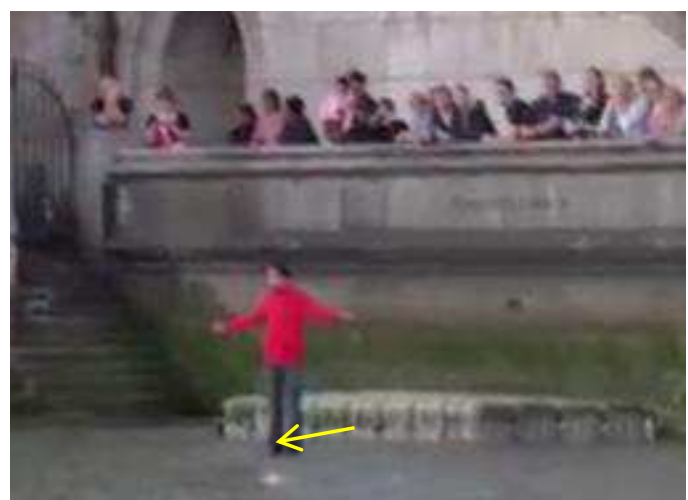

(a)

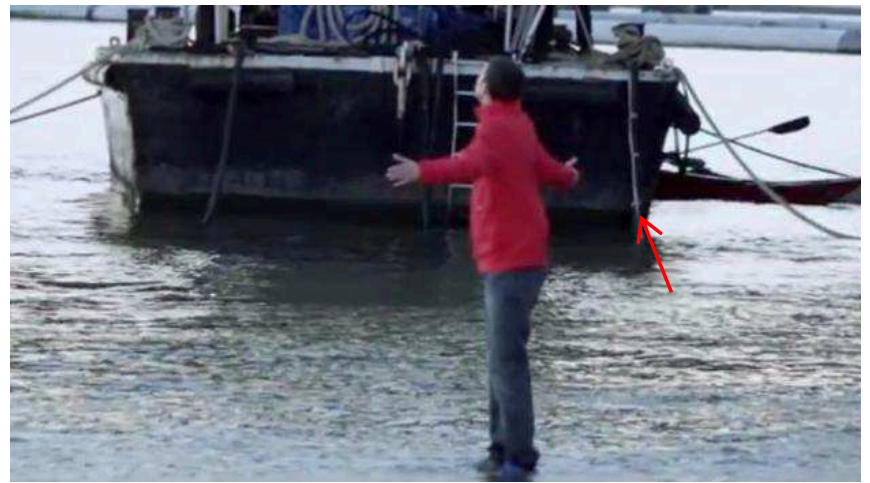

(b)

Fig. 3 - (a) Bolhas (seta) denunciam a presença de possíveis mergulhadores no local. (b) Barco de apoio logístico e de isolamento da área. Os caiaques (seta) saem de trás do barco (Dynamo, 2014).

Assim, chegou a hora de revelar o segredo de Dynamo. Em algum momento, possivelmente à noite, foi construída uma trilha submersa na margem do rio, apoiada em seu leito. Naquele ponto, o rio é mais largo que a média e parte da margem não é muito profunda, o que viabilizou o assentamento de plataformas apoiadas no leito do rio. As plataformas devem ter pernas retráteis, o que facilitou seu nivelamento. Para isolar a construção submersa do acesso ao público, uma vez que curiosos poderiam tentar reproduzir a caminhada de Dynamo, foi utilizada a plataforma flutuante que aparece na Fig. 2(a). Embora não tenha sido registrado no vídeo, esta plataforma deve ter sido retirada dali logo depois da dispersão dos expectadores.

É certo que o horário da apresentação foi escolhido com cuidado, pois ocorreu no fim da tarde, contra o Sol. O fato de o céu estar parcialmente nublado em nada atrapalhou o show. Ainda assim, havia muito reflexo nos olhos dos expectadores. Durante a caminhada, as tomadas de câmera também foram feitas contra o sol, tirando vantagem da luminosidade na superfície do rio. Para exemplificar como o uso oportuno da luz do Sol facilita a vida dos mágicos, há outro vídeo em que um homem caminha praticamente sobre a água de um lago e o truque é bem oculto pelo reflexo da luz (IFACT-WELL, 2011). Neste caso havia uma plataforma a cerca de um centímetro sob a água.

Ao longo da caminhada de Dynamo devia haver mergulhadores em torno da plataforma. Esta suspeita é reforçada pela presença de raras bolhas na superfície da água, detectada durante o vídeo (Fig. 4a). A função dos mergulhadores era certamente a de simular um afogamento (com desaparecimento) do mágico, caso ele caísse na água. Esta seria a melhor estratégia em caso de queda. Não seria nada bom para a carreira de Dynamo se ele tivesse de voltar todo molhado para o público. 
O barco que aparece nas proximidades da caminhada provavelmente deu suporte logístico e garantiu algum isolamento ao local. Também é possível ver que os dois caiaques que passam sobre a plataforma saíram detrás desse barco (Fig. 4b). Ou seja, os remadores certamente fazem parte do número. Por falar nisso, o calado dos caiaques é tão pequeno que isso não representou problema para a plataforma submersa.

Finalmente, a "detenção" de Dynamo ao final do número não passou de uma estratégia para que ele não tivesse de retornar exatamente pelo mesmo caminho da ida, o que seria muito suspeito. Além disso, não fez mal algum à imagem de Dynamo ser aprisionado pelas autoridades de Londres. Cristo também não foi aprisionado pela autoridade romana de Jerusalém?

\section{Considerações finais}

O uso de vídeos de números de mágica durante as aulas de Física pode constituir numa excelente estratégia de ensino, desde que alguns cuidados sejam tomados. A proposta da mágica em questão deve ser a de desafiar uma importante lei da Física da forma mais inusitada e audaciosa possível. O professor deve conhecer previamente o segredo da mágica com bastante confiança. Tentar desvendar o truque por conta própria pode ser desastroso. O professor também deve preparar previamente uma lista de possíveis hipóteses explicativas com alternativas variadas, umas descabidas, outras improváveis e algumas poucas possíveis. Quanto maior a variedade das hipóteses, maiores as chances de engajamento da classe como um todo. É a lista de hipóteses e as tentativas de refutação que trarão a Física para o centro das atenções. Se os alunos tiverem dificuldade para compor uma lista satisfatória, o professor deverá tentar induzi-los com pequenas pistas sobre uma ou outra hipótese. O processo de refutação deverá ser bastante rigoroso e os alunos devem obrigatoriamente concordar com o motivo de determinada hipótese ter sido refutada. Certamente será necessário introduzir ou revisar algum conceito, princípio ou lei física. Como isso pode demandar tempo de aula, o professor deve preparar com bastante objetividade o material a ser utilizado nesta etapa. Uma vez conhecida a hipótese sobrevivente, devem ser coletadas evidências para tentar comprová-la. Naturalmente que o professor deverá ter na ponta da agulha algum material didático para ilustrar a comprovação. No final das contas, a estratégia como um todo é um delicioso jogo de detetive.

\section{Referências bibliográficas}

ANGEL, C. (A\&E) Criss Angel Mindfreak. 2005. Disponível em: $<$ https://crissangel.com/mindfreak>. Acesso em: 29 ago. 2014.

ANGOTTI, J. A. P.; BASTOS, F. D. P. D.; MION, R. A. Educação em física: discutindo ciência, tecnologia e sociedade. Ciência \& Educação, v. 7, n. 2, p. 183-197, 2001. 
BLAINE, D. (NBC) Street Magic. 1997. Disponível em:

$<$ http://davidblaine.com/video/street-magic/>. Acesso em: 25 ago. 2014.

(NBC) Magic Man. 1998. Disponível em: <http://www.imdb.com/title/tt0248747/>. Acesso em: 22 ago. 2014.

BROWN, D. (Channel 4) Mind Control. 2000. Disponível em:

$<$ http://www.channel4.com/programmes/derren-brown-mind-control/>. Acesso em: 21 ago. 2014.

COPPERFIELD, D. (YouTube) Vanishing the Statue of Liberty. 1983. Disponível em: $<$ https://www.youtube.com/watch?v=Z0mKROBCbDI>. Acesso em: 22 ago. 2014.

(YouTube), Walking Through the Great Wall of China. 1986. Disponível em: <https://www.youtube.com/watch?v=JpG7w_EaUFY>. Acesso em: 22 ago. 2014.

(YouTube) The Magic of David Copperfield. 2013. Disponível em: <https://www.youtube.com/watch?v=Z0mKROBCbDI>. Acesso em: 22 ago. 2014.

DELIZOICOV, D.; ANGOTTI, A. P. Física. 2. ed. São Paulo: Cortez, 1992.

DOMINGOS, P. The role of Occam's Razor in knowledge discovery. Data Mining and Knowledge Discovery, v. 3, n. 4, p. 409-425, 1999.

FRAYNE, S. (UKTV \& UNI) Dynamo: magician impossible. 2011. Disponível em: <http://watch.uktv.co.uk/shows/dynamo-magician-impossible/>. Acesso em: 20 ago. 2014.

FREIRE, P. Pedagogia do oprimido. 17. ed. Rio de Janeiro: Paz e Terra, 1987.

GARDNER, M. Martin Gardner Centennial Collection: Articles from American Journal of Physics and The Physics Teacher 2014. Disponível em:

<http://www.aapt.org/Resources/Martin-Gardner-Centennial-Collection.cfm>. Acesso em: 14 mar. 2015.

GILLASPY, J. D. Martin Gardner: 100 Years of the Magic of Physics. The Physics Teacher, v. 52, n. 7, p. 394-395, 2014.

HANLIN, B. et al. (Discovery Channel) Ciência Mágica. 2013. Disponível em: $<$ http://www.discoverychannel.com.pt/programas-tv/a-ciencia-da-magia/>. Acesso em: 02 set. 2014.

IFACT-WELL (YouTube) Dynamo Walks on Water REVEALED Criss Angel walking: Magic Tricks. 2011. Disponível em: <https://www.youtube.com/watch?v=spNsoxqTR8s >. Acesso em: 04 set. 2014.

MOREIRA, M. A. Aprendizagem significativa. Brasilia: Universidade de Brasilia, 1999. 
A teoria da aprendizagem significativa e sua implementação em sala de aula. Brasília: Editora Universidade de Brasília, 2006.

MOREIRA, M. A.; MASINI, E. A. S. Aprendizagem significativa: A teoria de aprendizagem de David Ausubel. 2. ed. São Paulo: Centauro Editora, 2006.

MOREIRA, M. A.; OSTERMANN, F. Sobre o ensino do método científico. Caderno Catarinense de Ensino de Física, v. 10, n. 2, p. 108-117, 1993.

POPPER, K. Conjecturas e refutações. Brasília: Universidade de Brasília, 2008.

SIC (YouTube) Andar em cima da água. 2009. Disponível em:

$<$ https://www.youtube.com/watch?v=_WzutLYQLS0>. Acesso em: 27 ago. 2014.

SILVEIRA, A. F. D.; ATAÍDE, A. R. P. D.; FREIRE, M. L. D. F. Atividades lúdicas no ensino de ciências: uma adaptação metodológica através do teatro para comunicar a ciência a todos through theater for communicating science to all. Educar em Revista, n. 34, p. 251$262,2009$.

UKTV (YouTube) Dynamo: Magician Impossible. 2011. Disponível em: $<$ https://www.youtube.com/watch?v=DucNkGU1vcE>. Acesso em: 25/08/2014.

VALENTINO, V. (Fox Network) Breaking the magician's code: magic's biggest secrets finally revealed. 1997. Disponível em:

<http://www.imdb.com/title/tt0207261/?mode=desktop>. Acesso em: 01 set. 2014.

. (TV Globo) Fantástico - Mr. M. 1999. Disponível em:

$<$ http://memoriaglobo.globo.com/programas/jornalismo/programas-jornalisticos/fantastico/oprincipe-negro-dos-sortilegios.htm>. Acesso em: 27 ago. 2014.

WALES, J. Magic (illusion). Wikipedia: The Free Encyclopedia. San Francisco-CA: Wikipedia 2015. 